\title{
Semantic priming in the pronunciation of words in two writing systems: Italian and English
}

\author{
PATRIZIA TABOSSI and LINDA LAGHI \\ Università di Bologna, Bologna, Italy
}

\begin{abstract}
Semantic priming effects in naming Italian and English words were investigated. Experiments 1 and 2 were in Italian. In Experiment 1, the subjects named a target word, which was either associated with or unrelated to a preceding prime. The results showed semantic priming effects. However, in Experiment 2, in which the same materials occurred in a list that also included pseudowords, priming effects were obtained with the lexical decision task, but not with pronunciation. In Experiment 3, the inclusion of pseudowords in the materials prevented priming effects from occurring in Italian, but not in English. Finally, Experiment 4 indicated that, even in Italian, nonlexical reading was abandoned when a few of the to-be-pronounced items required lexical knowledge for correct stress assignment. The findings suggest that reading normally occurs lexically. The characteristics of the various writing systems, however, are relevant in determining the strategies that people may adopt in unusual circumstances.
\end{abstract}

Reading a word is the process by which a string of letters makes contact with the corresponding lexical representation, activating different types of information, including its semantics and phonology. An important issue in the study of reading is the nature of the code that allows this process of matching to occur. To date, many researchers agree that most common words are read on the basis of a visual code that activates the information relative to those words directly via orthography (Coltheart, 1978; Davelaar, Coltheart, Besner, \& Jonasson, 1978; Henderson, 1982; Patterson, 1982; Seidenberg, 1985a, 1985b; Seidenberg \& McClelland, 1989).

Part of the experimental evidence in support of this view comes from studies done with the naming task. It is well known, for instance, that frequent words are pronounced faster than less frequent words (Forster \& Chambers, 1973; Frederiksen \& Kroll, 1976; Glanzer \& Ehrenreich, 1979; Rubenstein, Lewis, \& Rubenstein, 1971). This is true not only for regular, but also for irregular words. Various studies have shown, in fact, that regular words are pronounced faster than irregular ones when they are low-frequency words but that the difference becomes smaller or even disappears for high-frequency words (Andrews, 1982; Seidenberg, 1985b; Seidenberg, Waters, Barnes, \& Tanenhaus, 1984; Waters \& Seidenberg, 1985). A commonly accepted explanation of this phenomenon, based on the distinction between whole-word and assembled phonology, is that the lexicon is involved in the pronunciation of common words, including irregular ones,

This research was supported by Grant 8700322 from the Ministero Pubblica Istruzione, Fondi $60 \%$. We would like to thank Derek Besner, Cristina Burani, Cristina Cacciari, Corrado Cavallero, Lucia Colombo, and Donia Scott for their useful suggestions. We are also grateful to three anonymous reviewers who helped us to improve the paper considerably. Requests for reprints should be sent to Patrizia Tabossi, Dipartimento di Psicologia, Viale Berti-Pichat 5, 40127 Bologna, Italy. and that only infrequent words require phonological mediation, which is typically assumed to take longer than whole-word phonology (Besner, 1984; Seidenberg, 1985a).

Effects of this sort are well established in English. But to what extent can the findings-and hence theories of reading based on them-be generalized to apply to other languages? Languages differ in many ways, one being how their orthography represents their phonology. At one extreme, there are languages, such as Chinese, in which the relation of spelling to sound is largely arbitrary. At the other extreme, there are languages, such as SerboCroatian, in which orthography represents phonology in a direct and unambiguous way. These differences lie on a continuum along which English appears to have systematic relations between its orthography and its phonology, but these relations are not transparent (Rozin \& Gleitman, 1977).

Given such large differences, it is reasonable to wonder whether lexical involvement in word pronunciation varies depending on the characteristics of the writing system of a language. Evidence that this may be the case comes from Frost, Katz, and Bentin (1987). They investigated word pronunciation in three languages whose orthographies differ in depth: Hebrew, whose orthography is the deepest of the three; English, whose orthography is of intermediate depth; and Serbo-Croatian, whose orthography is shallow. The findings suggested that the effects of the lexical status of the stimulus items-that is, whether they were high-frequency words, low-frequency words, or nonwords-were largest in Hebrew, next largest in English, and smallest in Serbo-Croatian. These results, however, are hardly compelling. In particular, although there was a tendency for Hebrew to be more sensitive than English to the effects of frequency and word superiority, no reliable difference between the two languages was reported. In contrast, several lines of investigation have shown that 
the lexicon is largely involved in the pronunciation of English words (Forster, 1979; Theios \& Muise, 1977), and comparable frequency effects have been found in the naming of English and Chinese words, in spite of the differences between the two writing systems (Seidenberg, 1985b). Thus, there seems to be little doubt that to pronounce a common word in English requires processes that are not different from the processes required in reading common words in languages with a deeper orthography (Bentin, Bargai, \& Katz, 1984; Bentin \& Frost, 1987).

The picture is less clear if one considers languages with shallow orthographies. Here, the effects that are typically investigated in order to establish lexical involvement in word pronunciation have yielded contradictory results. Frost et al. (1987), for instance, failed to find frequency effects in Serbo-Croatian, but these effects have been reported for both Dutch (Hudson \& Bergman, 1985) and Italian (Colombo, 1991).

Semantic priming effects are also not clear. In English, the phenomenon is well established: a word (e.g., BUTTER) is named faster when it follows an associated word (e.g., BREAD) than when it follows an unrelated word (e.g., TABLE). Given that in English reading common words aloud is accomplished lexically, it is not surprising that the naming task in that language is sensitive to factors such as the semantic organization of the lexicon as reflected in the associative facilitation effects. In languages with shallow orthographies, however, semantic priming effects have been found in some studies (Carello, Lukatela, \& Turvey, 1988; de Groot, 1985; Lukatela, Feldman, Turvey, Carello, \& Katz, 1989; Seidenberg \& Vidanovic, 1985 ), but they have not been observed in others (Frost et al., 1987; Katz \& Feldman, 1983).

In an attempt to shed some light on the issue, in the present article we investigate whether semantic priming affects word pronunciation in Italian, and if so, whether the conditions under which such effects occur differ in Italian and English. The purpose of the study reported here was threefold. First, evidence on whether and when semantic priming occurs in the naming of Italian words could be used to elucidate the discrepancy existing in the current literature. In Italian, the correspondence between orthography and phonology is very close, with only few, entirely predictable, variations. Thus its writing system can safely be considered shallow.

Second, the predictions of two different views of how orthography affects reading processes were tested. According to one hypothesis, the same basic processes occur across languages, regardless of the specific characteristics of the various writing systems (Besner \& Hildebrand, 1987; Seidenberg, 1985a, 1985b). In the so-called time course model (Seidenberg, 1985a), for instance, most words are recognized directly and automatically via orthography. They are named lexically, and whole-word output phonology rather than assembled phonology is used to perform the task. Only very uncommon, low-frequency words require phonological mediation in order to be recognized. Here, the specific characteristics of the different writing systems are not crucially relevant. Regardless of such characteristics, the orthographic and phonological information about a written string is assumed to become available to the word recognition system, which operates interactively, at different points in time. Recognition starts from the extraction of visual information from the input, and on most occasions, orthographic information is sufficient to gain access to the corresponding lexical item, before phonological information is retrieved. (but cf. Seidenberg \& McClelland, 1989, for a different view).

Alternatively, it has been claimed that the characteristics of the different writing systems play a crucial role in how people read words aloud. In particular, while word recognition in a shallow orthography is mediated primarily by a phonological, prelexical code, in a deep orthography it relies on orthographic cues and phonology is derived from the lexicon (Carello et al., 1988; Feldman \& Turvey, 1983; Frost et al., 1987; Turvey, Feldman, \& Lukatela, 1984). According to this hypothesis, languages such as Chinese, in which a skilled reader can only guess how to pronounce a new word, would require lexical activation; whole-word phonology would be retrieved from the lexicon and used for naming. In contrast, in languages such as Serbo-Croatian or Italian, in which a skilled reader can read correctly any new word (but see Colombo, 1991, for how stress assignment occurs), naming requires no access to the lexicon and may be performed by assembling the pronunciation of the word. Establishing whether semantic priming effects differ in Italian and in English will allow us to clarify the relevance of the characteristics of the various writing systems to reading processes.

Finally, in this work we investigated the appropriateness of the semantic priming effect, as it is reflected in the lexical decision and in the naming tasks, to languages with shallow orthography. This effect forms the basis of one of the most widely employed experimental paradigms in the study of such central topics as lexical organization (Fischler, 1977; Meyer, Schvaneveldt, \& Ruddy, 1974; Neely, 1977), lexical ambiguity (Swinney, 1979; Tabossi, 1988; Tanenhaus, Leiman, \& Seidenberg, 1979), and word recognition (Forster, 1981; Stanovich \& West, 1983). Admittedly, the semantic priming paradigm is rather problematic, and both the lexical decision and the naming tasks used in conjunction with it are open to a number of criticisms (Balota \& Chumbley, 1985; Chumbley \& Balota, 1984; Forster, 1981; Keefe \& Neely, 1990). In recent years, however, it has often been suggested that naming is relatively less likely to be affected by undesirable factors such as strategic and backward priming effects (Seidenberg, Waters, Sanders, \& Langer, 1984; Stanovich $\&$ West, 1983). Consequently, the naming task has become increasingly popular among researchers who deal with English. But it is still unclear whether naming can be fruitfully used in languages with shallower orthographies.

Hence, a reasonable approach to ascertaining whether semantic priming affects pronunciation in a shallow orthography is to study a language such as Italian, and to enhance lexical processing by encouraging the subjects 
to perform the naming task lexically (de Groot, 1985). To this end, all the targets in Experiment 1 were proper, frequent Italian words. The subjects were presented with a target word shortly after another word (prime). The words in each pair were either semantically associated, like CANE-GATTO (DOG-CAT), or unrelated, like LATTEGAMBA (MILK-LEG). The subjects' task was to read the prime silently and then to name the target as quickly as they could.

Under these conditions, only if naming is performed lexically should one expect semantic priming to occur. Priming would be revealed by a significant difference between associated and unrelated targets, the former being pronounced faster than the latter.

\section{EXPERIMENT 1}

\section{Method}

Subjects. A total of 20 undergraduates, all native speakers of Italian, volunteered for the experiment, which lasted about $15 \mathrm{~min}$. None of the subjects had previously participated in an experiment of this sort.

Materials. Forty pairs of words were selected. A total of 20 highly semantically associated pairs were chosen; 15 of them were derived from Parisi and Pizzamiglio (1967), who provide association norms for Italian akin to those in Palermo and Jenkins (1964). For each of these pairs, the target was the first or second ranking associate with respect to its prime. For the remaining five pairs, which were not included in Parisi and Pizzamiglio (1967), the strength of association between primes and targets was assessed by asking 20 Italian speakers to produce the first word that came to mind in response to each of 80 prime words read to them in a random order by the experimenters. For the five selected pairs, all the speakers produced targets that were the first or second associates of their primes. This procedure was made necessary by the low number of words (159 nouns and/or adjectives) for which association norms are available in Italian.

The remaining half of the pairs were semantically unrelated according to the authors' intuition. To prevent the possibility that the presence or absence of priming effects might be due to some specific semantic relations between primes and targets (Becker, 1979; Lupker, 1984), such relations, when existing, were made to vary across materials (see Appendix A). All the words were two or three syllables long and were of medium to high frequency of occurrence (mean frequency $=138, S D=150$ out of $1,500,000$; Istituto di Linguistica Computazionale di Pisa, 1989). The trisyllabic targets were stressed on the penultimate syllable, as in the majority of the polysyllabic words in Italian.

To ensure that naming times for the associated and the unrelated targets in isolation were comparable, the following pretest was carried out. A list of 126 words, including the $\mathbf{4 0}$ targets, was constructed and presented in random order to 10 subjects, whose task was to pronounce each word as quickly as possible. The results showed that the mean naming latencies and standard deviations for the 20 associated and the 20 unrelated targets were $457 \mathrm{msec}, S D=$ 18 , and $458 \mathrm{msec}, S D=21$, respectively $[\mathrm{t}(38)=.10$, n.s.].

Procedure and Design. The stimuli were displayed on the monitor of an Apple Ile microcomputer. Each trial was preceded by a tone followed, after $0.5 \mathrm{sec}$, by the prime, which was presented for $400 \mathrm{msec}$. The target appeared on the screen $100 \mathrm{msec}$ after the offset of the prime and stayed on for $1.5 \mathrm{sec}$. Simultaneous with the onset of the target was the starting of a timer, which was either stopped by the subject's response or (if the subject did not respond) reset automatically after $1.5 \mathrm{sec}$. There was a $3-\mathrm{sec}$ interval between trials.

In the experimental list, which was preceded by 20 practice trials, the trials appeared in a quasirandom order, with the constraint that no more than three associated or unrelated pairs occur in a row. The importance of being fast and accurate was stressed with all the subjects, who were tested individually and acted as their own controls.

\section{Results and Discussion}

The mean reaction times for correct responses (RTs), $S D$ s, and mean percentages of errors in the associated and unrelated conditions are shown in Table 1. Latencies to pronounce associated and unrelated targets differed significantly both in the analysis by subjects and in the analysis by items $[r(19)=2.88, p<.005$, one-tailed, and $t(38)=1.84, p<.05$, one-tailed, respectively]. Errors showed a similar pattern, although the difference between the related and unrelated conditions reached significance in the analysis by subjects, but only approached it in the analysis by items $[t(19)=3.29, p<.001$, one-tailed; $t(38)=1.35, p<.09$, one-tailed $]$.

The findings show that common Italian words are pronounced faster following an associated than following an unrelated word. Thus, although the targets could have been named accurately by the subjects on the basis of assembled phonology without their relying on lexical information, Experiment 1 suggests that the task was largely performed lexically.

These results replicate those of de Groot (1985), Seidenberg and Vidanovic (1985), and Lukatela and colleagues (Carello et al., 1988; Lukatela et al., 1989). Also, they are consistent with those of Colombo (1991), who has reported frequency effects in Italian. But how can they be reconciled with the contrasting findings reported by Katz and Feldman (1983) and Frost et al. (1987)? One possibility is that in Katz and Feldman (1983) and Frost et al. (1987), unlike in other studies, the related pairs were semantically, but not associatively, related. It has accordingly been argued that the nonassociative relation may not have been strong enough to elicit semantic priming ( $\mathrm{Ca}$ rello et al., 1988). There is, however, some evidence that semantically related primes can affect the pronunciation of English words (Schreuder, Flores d'Arcais, \& Glazenborg, 1984; Seidenberg, Waters, Sanders, \& Langer, 1984; but cf. Lupker, 1984, for a different view). Also, in Katz and Feldman (1983) and Frost et al. (1987), the semantic nonassociative relation did give rise to the

Table 1

Mean Response Times (in Millseconds), With Standard Deviations, to Correct Responses, and Mean Percentages of Error to Probounce Target Words in the Associated and the Unrelated Conditions in Experiments 1 and 4 (Italian)

\begin{tabular}{cccccccc}
\hline & \multicolumn{3}{c}{ Associated } & & \multicolumn{3}{c}{ Unrelated } \\
\cline { 2 - 4 } \cline { 6 - 8 } Experiment & RT & $S D$ & \% Error & & RT & $S D$ & \% Error \\
\hline 1 & 431 & 68 & 1.75 & & 445 & 71 & 5.25 \\
4 & 463 & 34 & 0.25 & & 478 & 35 & 0.25 \\
\hline
\end{tabular}


priming effect in Hebrew and in English, thus suggesting that the relation alone cannot be responsible for the discrepancy.

Perhaps a more promising explanation is that while nonwords were not included in de Groot (1985), in Seidenberg and Vidanovic (1985), or in the present Experiment 1, they were present in both Katz and Feldman (1983) and Frost et al. (1987), and the occurrence of these items might have influenced the way in which actual words were pronounced. Admittedly, pseudowords did not prevent semantic priming effects from occurring in Carello et al. (1988) and Lukatela et al. (1989), in which subjects pronounced Serbo-Croatian words. Pseudowords in those studies, however, were close derivations of the target words (e.g., Tosa from the word for hair, KosA) and were preceded, in the related condition, by priming words that were associated to the source words (e.g., the word for comb, CESALJ). Such characteristics have probably induced ad hoc strategies in the subjects, as is strongly suggested by the fact that in Carello et al. (1988), the related condition produced a significant facilitatory effect in naming not only words but also pseudowords. Evidently, the latter were processed as derivations from specific lexical items rather than as meaningless strings (Rosson, 1985). In addition, neither frequency nor stress of the longer words was controlled in Carello et al. (1988) and Lukatela et al. (1989). Given the peculiar aspects of these studies, it remains possible to claim that the presence or absence of pseudowords in the materials explains the discrepancy between de Groot (1985), Seidenberg and Vidanovic (1985), and the present experiment, on the one hand, and Katz and Feldman (1983) and Frost et al. (1987), on the other. Testing this hypothesis was the main focus of Experiment 2.

Here the same associated and unrelated pairs that were used in Experiment 1 occurred in a list that also included an equal number of pairs whose targets were nonwords. The new list was presented to two groups of subjects. One was assigned to a lexical decision task (lexical decision group), and one was assigned to the naming task (naming group).

If the hypothesis above is correct, semantic priming should affect lexical decision, which can only be performed by checking to determine whether or not the target is a known word in the lexicon. Naming a word in a language with a shallow orthography, however, may not require a similar process and can be carried out in the same way as naming a nonword-that is, nonlexically. Hence, one should expect semantic association to produce an effect in the lexical decision group, but not in the naming group, giving rise to an interaction between the two factors.

\section{EXPERIMENT 2}

\section{Method}

Subjects. A total of 20 undergraduates volunteered for the experiment, which lasted about $25 \mathrm{~min}$. All the subjects were native speakers of Italian, and none of them had previously participated in an experiment of this sort.
Materials. The same 20 pairs of word associates and 20 pairs of unrelated words used in Experiment 1 were employed here. To make sure that lexical decision times on the $\mathbf{4 0}$ targets in isolation were comparable, a pretest similar to that carried out in Experiment 1 was devised. The $\mathbf{4 0}$ words were included in a list of 150 words and 150 legal nonwords. The 300 items, randomly divided in five blocks of 60 trials, were presented, each for $1.5 \mathrm{sec}$, to 15 subjects who performed a lexical decision task on them. The results showed that the mean RTs and SDs to the associated and unrelated targets were $528 \mathrm{msec}, S D=29$, and $528 \mathrm{msec}, S D=30$, respectively $[t(38)=.04$, n.s.].

In addition to the associated and unrelated pairs, 40 pairs were also constructed in which the prime was a meaningful Italian word and the target was a legally pronounceable nonword. The materials thus obtained were included in the experimental list, which yielded a total of 80 trials.

Procedure and Design. The procedure and apparatus were the same as in Experiment 1, with two exceptions. First, the experimental list was presented in two blocks of $\mathbf{4 0}$ trials, each including an equal number of word and nonword targets. Within each block, the trials appeared in a quasirandom order, the constraint being that no more than three target words or nonwords occur in a row. Second, an equal number of subjects, randomly assigned to the lexical decision and naming groups, was given the same experimental list, preceded by 20 practice trials. The subjects in the lexical decision group were instructed to respond by pressing a key with their dominant hand when the target was a word and by pressing another key with the other hand when the target was a nonword. The subjects in the naming group were instructed to read all the targets aloud, regardless of whether they were words or nonwords. Within each group, the subjects acted as their own controls.

\section{Results and Discussion}

The mean RTs and SDs to correct word responses and the percentages of incorrect responses for the different experimental conditions are shown in Table 2.

The analyses of variance included two factors: task (lexical decision vs. naming) and type of semantic relation (associated vs. unrelated). When latencies were treated as the dependent variable, the results showed a significant effect of task [analysis by subjects, $F(1,38)=7.17$, $M S_{\mathrm{e}}=5,775, p<.05$; analysis by items, $F(1,38)=$ 63.37, $M S_{\mathrm{e}}=691, p<.001 ; \min F^{\prime}(1,47)=6.44$, $p<.02]$. The interaction between task and type of semantic relation was also significant [analysis by subjects, $F(1,38)=25.39, M S_{\mathrm{e}}=320, p<.001$; analysis by items, $F(1,38)=10.65, M S_{\mathrm{c}}=691, p<.001 ; \min$ $\left.F^{\prime}(1,65)=7.50, p<.01\right]$. Instead, the type of semantic relation was significant in the analysis by subjects $\left[F(1,38)=14.84, M S_{\mathrm{e}}=320, p<.001\right]$, but not in that by items $[F(1,38)=2.52$, n.s.].

Separate analyses showed that in the lexical decision group the associated targets were responded to faster than

Table 2

Mean Response Times (in Milliseconds), With Standard Deviations, to Correct Word Responses, and Mean Percentages of Error

in Lexical Decision and Naming Tasks for the Associated and Unrelated Conditions in Experiment 2 (Italian)

\begin{tabular}{lccccccc}
\hline & \multicolumn{3}{c}{ Associated } & & \multicolumn{3}{c}{ Unrelated } \\
\cline { 2 - 4 } \cline { 6 - 8 } \multicolumn{1}{c}{ Task } & RT & $S D$ & \% Error & & RT & SD & \% Error \\
\hline Lexical decision & 509 & 37 & 2.25 & & 545 & 45 & 6.50 \\
Naming & 484 & 70 & 0.25 & & 479 & 63 & 0.75 \\
\hline
\end{tabular}


the unrelated targets [analysis by subjects, $F(1,38)=$ $39.49, p<.001$; analysis by items, $F(1,38)=7.45, M S_{\mathrm{e}}$ $=1,396, p<.05]$. In contrast, no significant difference was observed in the naming group [analysis by subjects, $F(1,38)=0.70$, n.s.; analysis by items, $F(1,38)=0.57$, n.s.] (Bruning \& Kintz, 1977).

When the percentage of errors was treated as the dependent variable, the overall analysis showed a significant effect of task [analysis by subjects, $F(1,38)=19.44$, $M S_{\mathrm{e}}=0.61, p<.001$; analysis by items, $F(1,38)=$ $25.82, M S_{\mathrm{e}}=0.47, p<.001 ; \min F^{\prime}(1,75)=11.09$, $p<.005$ ]. Semantic relation was also significant [analysis by subjects, $F(1,38)=9.98, M S_{\mathrm{e}}=0.45, p<.001$; analysis by items, $F(1,38)=5.20, M S_{\mathrm{e}}=0.86, p<.05$; $\left.\min F^{\prime}(1,69)=3.42, p<.06\right]$. The interaction between the two factors was significant in the analyses by subjects $\left[F(1,38)=6.22, M S_{\mathrm{e}}=0.45, p<.02\right]$ and by materials $\left[F(1,38)=6.04, M S_{\mathrm{e}}=0.47, p<.02\right]$, although the $\min F^{\prime}$ only approached significance $\left[\mathrm{min} F^{\prime}(1,76)\right.$ $=3.07, p<.08$ ].

Again, separate analyses showed that in the lexical decision group, subjects made fewer errors in the associated than in the unrelated condition [analysis by subjects, $F(1,38)=15.98, p<.001$; analysis by items, $F(1,38)=$ $\left.5.82, M S_{e}=1.24, p<.05\right]$. In the naming group, no reliable difference was observed [analysis by subjects, $F(1,38)=0.22$, n.s.; analysis by items, $F(1,38)=1.08$, n.s.].

Subjects' performance on unrelated words and nonwords was also compared. When latencies were treated as the dependent variable, the results showed a significant effect of task. Subjects in the lexical decision group responded to both unrelated words and nonwords more slowly than did subjects in the naming group [575 vs. $496 \mathrm{msec}$; analysis by subjects, $F(1,38)=18.88, M S_{e}=$ $6,540, p<.001$; analysis by items, $F(1,58)=185.00$, $\left.M S_{\mathrm{e}}=904, p<.001 ; \min F^{\prime}(1,46)=17.13, p<.001\right]$. The difference between unrelated words and nonwords (511 vs. $559 \mathrm{msec}$ ) was also reliable [analysis by subjects, $F(1,38)=41.47, M S_{\mathrm{e}}=1,434, p<.001$; analysis by items, $F(1,58)=69.08, M S_{\mathrm{e}}=875, p<.001 ; \min$ $\left.F^{\prime}(1,79)=25.90, p<.001\right]$. The interaction between task and type of words was reliable in the analysis by items $\left[F(1,58)=5.19, M S_{e}=904, p<.05\right]$, but not in that by subjects $[F(1,38)=2.33$, n.s. $]$.

Furthermore, when the percentage of errors was treated as the dependent variable, the analyses showed that subjects in the lexical decision group made more errors at responding to both unrelated words and nonwords (7.33\%) than did subjects in the naming group $(3.58 \%)$ [analysis by subjects, $F(1,38)=6.21, M S_{e}=4.07, p<$ .05 ; analysis by items, $F(1,58)=15.70, M S_{\mathrm{e}}=1.22$, $\left.p<.001 ; \min F^{\prime}(1,67)=4.45, p<.05\right]$. The difference between unrelated words $(3.63 \%)$ and nonwords $(6.38 \%)$ was reliable in the analysis by subjects $\left[F(1,38)=26.40, M S_{\mathrm{e}}=2.52, p<.001\right]$ and in the analysis by items $\left[F(1,58)=4.35, M S_{\mathrm{e}}=1.85, p<\right.$ .05 ]; the $\min F^{\prime}$, however, did not reach significance [min
$F^{\prime}(1,76)=3.73$, n.s.]. Finally, the interaction between the two factors was significant neither in the analysis by subjects $[F(1,38)=0.04$, n.s. $]$ nor in that by materials $[F(1,58)=1.95$, n.s. $]$.

The results showed semantic priming effects in the lexical decision group but not in the naming group, thus replicating the results of Katz and Feldman (1983) and Frost et al. (1987), who failed to obtain these effects in Serbo-Croatian.

In conjunction with Experiment 1, this experiment seemed to support the hypothesis that semantic priming effects in naming words in languages with a shallow orthography may depend on the inclusion of nonwords in the materials. In fact, the studies that reported the effects either did not include pseudowords (de Groot, 1985; Seidenberg \& Vidanovic, 1985, Experiment 1) or included pseudowords that were likely to be processed as modified lexical items (Carello et al., 1988; Lukatela et al., 1989). In contrast, the studies failing to report the effect included pseudowords (Katz \& Feldman, 1983; Frost et al., 1987; the present Experiment 2).

The explanation above accounts for the presence or absence of semantic priming effects in languages with a shallow orthography by allowing the characteristics of the list to affect the way in which people accomplish reading in those languages. But do similar list effects also occur in writing systems that are phonologically less transparent? Should this not be the case, as suggested by some evidence (Frost et al., 1987; Keefe \& Neely, 1990; West \& Stanovich, 1982), an implication would be that although semantic priming effects on word pronunciation can operate regardless of the characteristics of the various writing systems, there are genuine cross-linguistic differences with respect to the conditions that allow the effects to occur. Experiment 3 was devised to elucidate this point.

Experiment 3 involved two groups of subjects: one whose language was English, and one whose language was Italian. Each group read aloud, as quickly as possible, strings of letters that were presented shortly after word primes and that were either legally pronounceable pseudowords or actual words in their respective languages. In the latter case, primes and targets could be associated or unrelated. If there are cross-linguistic differences in the robustness of lexical factors in word pronunciation, when nonwords are included in the experimental list one should expect semantic priming to occur in English, but not in Italian.

\section{EXPERIMENT 3}

\section{Method}

Subjects. A total of 36 subjects, 18 native speakers of English and 18 native speakers of Italian, volunteered for the experiment, which lasted about $20 \mathrm{~min}$. None of the subjects had previously taken part in an experiment of this sort.

Materials and Design. There were 18 English high-frequency associated word pairs, derived from Lupker's (1984) Experiment 4. Although a few of these pairs were also semantically related, most of them were not. The materials were selected from Postman and 
Keppel's (1970) association norms, so that the target in each pair was either the first or the second ranking associate of its prime. The 18 associated pairs were re-paired to form 18 unrelated pairs.

In addition, 18 word-pseudoword pairs were selected. The pseudowords were orthographically and phonologically legal, and were derived from Rubenstein et al. (1971). Two counterbalanced lists of stimuli were created, each of which contained half of the associated and half of the unrelated pairs, in addition to all the nonword pairs. Within each list, which accounted for a total of 36 trials, each item occurred only once.

A total of 18 Italian associated pairs were also selected from the pool used in Experiments 1 and 2 to match as much as possible the English materials both in length and strength of association. These materials were then re-paired to form 18 unrelated pairs. The words were of high to intermediate frequency of occurrence (mean frequency $=236, S D=198$, out of $1,500,000$; Istituto di Linguistica Computazionale di Pisa, 1989) (see Appendix B). In addition, 18 wordpseudoword pairs were selected from the pool used in Experiment 2.

As for the English materials, two counterbalanced lists were constructed, each of which contained half of the associated pairs, half of the unrelated pairs, and all the nonword pairs, thus yielding a total of 36 trials. Within each list, each item occurred only once.

Within each language group, an equal number of subjects, who acted as their own controls, was randomly assigned to one of the experimental lists.

Procedure. It was the same as in Experiment 2, with one exception. The two groups of subjects did not differ in task (both performed a naming task), but in their own language.

\section{Results and Discussion}

Mean RTs and SDs for correct word responses and percentages of errors to related and unrelated target words for the two language groups are presented in Table 3.

The analyses of variance included language (English vs. Italian) as a between-subject factor, and type of semantic relation (associated vs. unrelated) as a within-subject factor. When latencies were treated as the dependent variable, language was significant in the analysis by items, but not in that by subjects $\left[F(1,34)=20.32, M S_{\mathrm{e}}=510\right.$, $p<.001 ; F(1,34)=1.93$, n.s., respectively]. The effect of the type of semantic relation was significant both in the analysis by subjects $\left[F(1,34)=9.94, M S_{\mathrm{e}}=214\right.$, $p<.005]$ and in that by items $\left[F(1,34)=6.67, M S_{\mathrm{e}}=\right.$ $\left.399, p<.05 ; \min F^{\prime}(1,66)=3.99, p<.05\right]$; and so was the interaction between language and type of relation [analysis by subjects, $F(1,34)=8.01, M S_{\mathrm{c}}=214$, $p<.01$; analysis by items, $F(1,34)=4.41, M S_{\mathrm{e}}=399$, $p<.05$ ], although the $\min F^{\prime}$ only approached reliability $\left[\min F^{\prime}(1,63)=2.84, p=.09\right]$.

Separate analyses showed that in the English group, associated targets were named significantly faster than unrelated targets [analysis by subjects, $F(1,34)=17.90$,

Table 3

Mean Response Times (in Milliseconds), With Standard Deviations, to Correct Responses, and Mean Percentages of Error to Name Target Words Under the Associated and Unrelated Conditions in English and in Italian in Experiment 3

\begin{tabular}{lccccccc}
\hline & \multicolumn{3}{c}{ Associated } & & \multicolumn{3}{c}{ Unrelated } \\
\cline { 2 - 4 } \cline { 6 - 7 } Language & RT & $S D$ & \% Error & & RT & SD & \% Error \\
\hline English & 440 & 44 & 1.85 & & 461 & 44 & 2.47 \\
Italian & 428 & 53 & 1.85 & & 429 & 51 & 2.47 \\
\hline
\end{tabular}

$p<.001$; analysis by items, $F(1,34)=10.97, p<$ $.001]$. No reliable difference appeared in the Italian group [analysis by subjects, $F(1,34)=0.52$, n.s.; analysis by items, $F(1,34)=0.11$, n.s.].

When errors were treated as the dependent variable, no significant effect was observed for any of the sources or the interactions [analysis by subjects, language, $F(1,34)$ $=0.91$, n.s., type of relation, $F(1,34)=0.79$, n.s.; interaction between language and type of relation, $F(1,34)=$ 0.08 , n.s.; analysis by items, language, $F(1,34)=0.77$, n.s., type of relation, $F(1,34)=0.69$, n.s.; interaction between language and type of relation, $F(1,34)=0.74$, n.s.].

The subjects' performance at pronouncing nonwords was also analyzed. Italian unrelated words and pseudowords were pronounced 39 msec faster than English unrelated words and pseudowords ( 440 vs. $479 \mathrm{msec}$ ), a difference that was reliable both in the analysis by subjects and in that by items $\left[F(1,34)=7.16, M S_{\mathrm{e}}=3,375, p<\right.$ $.05 ; F(1,68)=72.21, M S_{\mathrm{e}}=413, p<.001$, respectively; $\min F^{\prime}(1,41)=6.51, p<.05$ ]. The 29 -msec difference between unrelated words and pseudowords (445 vs. $474 \mathrm{msec}$ ) was also significant both in the analysis by subjects $\left[F(1,34)=38.05, M S_{\mathrm{e}}=361, p<.001\right]$ and in that by items $\left[F(1,68)=36.90, M S_{e}=413, p<\right.$ $\left..001 ; \min F^{\prime}(1,92)=18.73, p<.001\right]$. The interaction, however, was significant neither in the analysis by subjects $[F(1,34)=2.91$, n.s. $]$ nor in the analysis by items $[F(1,34)=2.03$, n.s. $]$.

Furthermore, subjects made significantly more errors in pronouncing nonwords $(4.32 \%)$ than in pronouncing unrelated words $(2.47 \%)$ [analysis by subjects, $F(1,34)$ $=6.50, M S_{\mathrm{e}}=0.85 ; p<.05$; analysis by items, $F(1,68)$ $=10.03, M S_{\mathrm{e}}=0.55, p<.005, \min F^{\prime}(1,76)=3.94$, $p=.05]$. Neither language nor the interaction between language and lexicality of the targets was significant [analysis by subjects, language, $F(1,34)=1.65$, n.s.; interaction between language and lexicality, $F(1,34)=1.62$, n.s.; analysis by items, language, $F(1,68)=2.50$, n.s.; interaction, $F(1,68)=2.51$, n.s.].

The Italian data replicated the findings obtained by Frost et al. (1987) with Serbo-Croatian, corroborating the hypothesis that the occurrence of nonwords in the list does affect whether or not semantic priming effects are observed in naming words in languages with shallow orthographies. In English, however, in agreement with what has been observed in a number of studies (Frost et al., 1987; Keefe \& Neely, 1990; West \& Stanovich, 1982), the presence of nonword targets in the experimental list did not prevent semantic priming effects from being obtained.

Clearly, there are cross-linguistic differences in the extent to which lexical priming affects naming. But does this finding support the conclusion that reading processes differ depending on the writing systems (Carello et al., 1988; Frost et al., 1987; Katz \& Feldman, 1983; Lukatela et al., 1989)? Probably not. Even in shallow languages such as Italian or Serbo-Croatian, in fact, only mono- and bisyllabic words can safely be read nonlexically, whereas 
longer words require lexical knowledge for stress assignment (Colombo, 1991). In Frost et al. (1987) and Katz and Feldman (1983), this problem was finessed by using only bisyllabic target words. Likewise, in the present study most targets were bisyllabic, and the few trisyllabic words were all stressed on the penultimate syllable, like the vast majority of polysyllabic words in Italian. Actual texts, however, do not contain only short or regularly stressed words. They also include words that require lexical knowledge, and render nonlexical reading as unreliable in shallow orthographic systems as it is in deeper ones. Thus, though genuine, cross-linguistic differences may appear only when naming is performed under special conditions, whereas in normal circumstances people read most common words by relying on lexical knowledge, regardless of the characteristics of their writing systems.

If this view is correct, the occurrence of words requiring lexical information in a list that also includes pseudowords should induce in the Italian readers a lexical naming strategy akin to that observed in the English readers. Experiment 4 was devised to test this hypothesis. Here, Italian subjects were presented with a target word or pseudoword shortly after a word prime. Target words were either semantically associated with or unrelated to their primes. In addition to target words stressed on the penultimate syllable, the materials also included a small proportion of trisyllabic words whose stress was on the first syllable. Since this type of words makes lexical knowledge necessary for their correct pronunciation, the prediction was that semantic priming effects should appear and associated targets should be named faster than unrelated targets.

\section{EXPERIMENT 4}

\section{Method}

Subjects. A total of 20 subjects, all native speakers of Italian, volunteered in the experiment, which lasted about $20 \mathrm{~min}$.

Materials and Design. There were 40 pairs of highly associated words; for 26 of these pairs, the target was the first or second ranking associate for its prime in Parisi and Pizzamiglio (1967). The remaining 14 pairs were selected among those for which the 20 speakers of the pretest described in Experiment 1 produced targets that were the first or second associates of their primes. The target words were of high to intermediate frequency of occurrence (mean frequency $=181, S D=181$, out of $1,500,000$; Istituto di Linguistica Computazionale di Pisa, 1989). Half the target words were bisyllabic, and half were trisyllabic. Of the trisyllabic words, 12 were stressed on the second syllable, and 8 were stressed on the first syllable.

To reduce the percentage of associated pairs in the list, 10 filler pairs were constructed with no relation between prime and target. Of the filler targets, 5 were two syllables long, and 5 were three syllables long - three stressed on the second and two on the first syllable. Bi-and trisyllabic words were of comparable frequency.

In addition, 50 word-prime/nonword-target pairs were constructed. Nonwords, all of which were legal, were obtained by changing, adding, or deleting one letter from a real word. Half the target nonwords were two syllables long and half were three syllables long. The latter were derived from 15 words stressed on the second syllable and 10 words stressed on the first one.
Number of syllables, percentage of bi- and trisyllabic words, stress distribution, and mean frequency were comparable in the prime and in the target words. As in the previous experiments, practice trials contained the same percentage of different types of words and pseandowords as in the list proper.

Two counterbalanced lists of 100 pairs were constructed. Each list contained half of the target words paired with the originally associated primes and half re-paired to form semantically unrelated pairs. Both lists contained the same filler and word-prime/nonwordtarget pairs. Thus, on the two lists, each prime and each target $o$ curred once. (See Appendix C.)

An equal number of subjects was randomly assigned to one of the lists. The subjects acted as their own controls.

Procedure. The procedure was the same as in Experiment 1.

\section{Results and Discussion}

The mean RTs and SDs to correct word responses and mean percentages of errors in the associated and unrelated conditions are shown in Table 2. Latencies to pronounce associated and unrelated targets differed significantly both in the analysis by subjects $[t(19)=4.09, p<.005$, onetailed] and in the analysis by items $[t(39)=3.05, p<$ .005 , one-tailed]. When errors were treated as the dependent variable, no significant effect was observed either in the analysis by subjects or in that by items $[t(19)=$ 0 , and $t(39)=0.29$, respectively].

Nonwords were pronounced more slowly than unrelated words (506 vs. $478 \mathrm{msec}$ ). This difference was significant both in the analysis by subjects and in that by items $[t(19)=7.06, p<.001$, one-tailed; $t(78)=3.85, p<$ .001 , one-tailed, respectively]. Also, nonwords were mispronounced more often than unrelated words $(1.35 \%$ vs. $0.25 \%$ ) [analysis by subjects, $t(19)=3.19, p<.005$, one-tailed; analysis by items, $t(78)=2.70, p<.005$, one-tailed].

In agreement with the predictions, the experiment suggests that a small number of words whose correct stress assignment requires lexical knowledge is sufficient to produce semantic priming effects in Italian. Alternatively, one might claim that the overall priming observed in Experiment 4 is not due to the structure of the list affecting the way in which words, including bisyllabic ones, are pronounced. Rather, priming could result from the lexical reading of the trisyllabic words stressed on the first syllable, with very little or no change in how the rest of the words are pronounced. Separate analyses of the different types of items, however, showed significant semantic priming effects not only for the trisyllabic words stressed on the first syllable [associated words, $474 \mathrm{msec}$, $S D=32$; unrelated words, $493 \mathrm{msec}, S D=30 ; t(7)=$ $2.00, p<.05$, one-tailed], but also for the bisyllabic and trisyllabic words stressed on the second syllable [associated words, $461 \mathrm{msec}, S D=26$; unrelated words, $476 \mathrm{msec}, S D=30 ; t(31)=2.62, p<.001$, one-tailed]. Even bisyllabic words alone showed semantic priming effects [associated words, $458 \mathrm{msec}, S D=25$; unrelated words, $474 \mathrm{msec}, S D=26 ; t(19)=1.92, p<.05$, onetailed].

Indeed, the present findings suggest that not only in English, but also in Italian, common words are usually pro- 
nounced faster when they are preceded by semantically related primes rather than by unrelated primes, regardless of the occurrence of pseudowords in the list.

\section{GENERAL DISCUSSION}

The semantic priming effects obtained in Experiment 1 on the pronunciation of common Italian words suggest that as in languages with a deep orthography, reading in languages with a shallow orthography is usually performed lexically. Semantic priming effects, however, may disappear in a language with a shallow orthography, if items lacking lexical representations are introduced in a list of frequent, regularly stressed words. Under these conditions, actual words appear to be pronounced nonlexically, on the basis of assembly rather than whole-word phonology (Experiment 2). No comparable list effects have been observed in English, in which word reading can never be accomplished safely without reliance on lexical knowledge (Experiment 3 ). But nonlexical reading has a very limited use, even in a language with a very transparent orthography, like Italian. Indeed, a few items with an irregular stress are sufficient to induce the readers to abandon the nonlexical strategy, in favor of the lexical one, regardless of the presence of pseudowords in the list (Experiment 4).

It might be argued, perhaps, that the present findings do not justify the claim that in Experiment 2 and in the Italian part of Experiment 3 lexical knowledge was not involved in word pronunciation. Lexical knowledge, in fact, may have influenced the assembly of phonology (Besner \& Hildebrandt, 1987), as is also suggested by the robust difference observed between words and pseudowords in the preceding experiments.

This difference, however, does not necessarily call for a lexicality effect on reading. First, in the present study, pseudowords, although comparable with words in terms of number of letters and syllables, were not properly selected for comparison with them. Hence, the outcome of such comparison must be considered with great caution. Second, as Baluch and Besner (1991) have pointed out, the difference between words and pseudowords may not be due to faster activation for words in the lexicon, but to the output phonological code for words being more familiar and hence faster than the output phonological code for pseudowords. In fact, differences between words and pseudowords have been consistently shown in studies that have failed to yield typically lexical effects (Baluch \& Besner, 1991; Feldman \& Turvey, 1983; Katz \& Feldman, 1983), and the best way to reconcile these otherwise conflicting results is to locate lexical and word superiority effects at different points in the process of word pronunciation. Whereas lexical effects such as semantic priming would occur during identification, word superiority would take place at a later stage, during production, thus reflecting the sensitivity of the output lexicon to the phonological structure of actual words.
Taken together, and with the proviso that only frequent words have been considered in the present study, the findings above establish three major points. First, the seemingly contradictory results reported for semantic priming effects on naming in orthographically shallow languages are due to the different experimental conditions employed in the various studies. Semantic priming effects are consistently observed when the test trials are included in lists that either do not contain pseudoword targets (de Groot, 1985; Seidenberg \& Vidanovic, 1985; Experiment 1 here) or else include, in addition, words with an irregular stress pattern (Experiment 4). Instead, when experimental lists include regularly stressed words and pseudowords, no semantic priming effects are obtained (Frost et al., 1987; Katz \& Feldman, 1983; Experiment 2 and Italian group in Experiment 3 here).

Second, in the dispute between those who claim that lexical involvement in reading varies, depending on the print-to-sound correspondences in a language, and those who claim that such differences are not crucial to the nature of the reading processes, the present results seem to speak for the latter. It was already well known that in phonologically deep languages reading is performed lexically. The present results establish that, in ordinary circumstances, semantic priming does affect naming in languages with a shallow orthography. Thus, they extend evidence indicating that not only the Chinese, the Hebrew, or the English, but also the Serbo-Croatian, the Dutch, and the Italian rely on their lexical knowledge for reading and pronouncing most common words, regardless of the different characteristics of their writing systems.

Such characteristics do, however, have a role, and it comes into play when reading has to be performed in unusual conditions. Here, cross-linguistic differences appear. In languages with a deep orthography, actual words are read consistently through lexical output phonology, but in languages with a shallow orthography, this strategy can be abandoned in favor of nonlexical assembled phonology, when the regularity of the words and the introduction of pseudowords render that way safe and useful.

Strategic effects on word recognition are not surprising. Instructional manipulations and list manipulations of different sorts have all been shown to affect subjects' performance (Andrews, 1982; Becker, 1980; Coltheart, Besner, Jonasson, \& Davelaar, 1979; de Groot, 1984; Keefe \& Neely, 1990; Neely, 1977; Tweedy, Lapinski, \& Schvaneveldt, 1977).

Several authors have interpreted list effects as indicating the subjects' use of strategies in word recognition (Coltheart et al., 1979). An alternative view claims, in contrast, that the initial processes involved in reading are automatic, and the occurrence of strategic effects depends on the tasks-naming and lexical decision-employed in the various studies (Seidenberg, 1985a, 1985b). Lexical decision is a discrimination task, and can therefore be affected by subjects' response criteria. Naming, instead, does not allow such criteria to operate, and genuinely 
reflects the initial processes of word recognition. Consequently, effects due to the composition of the experimental lists should be observed in conjunction with the lexical decision, but not with the pronunciation task (Waters \& Seidenberg, 1985).

This explanation, however, does not seem to apply to the present results, in which semantic priming on word naming was observed or failed to be observed, depending on the characteristics of the experimental list. Clearly, the composition of the lists prompted the Italian subjects to pronounce at least a large number of target words lexically in Experiments 1 and 4, and nonlexically in Experiments 2 and 3 . This suggests that reading normally occurs lexically, regardless of the spelling-to-sound characteristics of the language involved. However, as is usually the case with processes that have become automatic through learning, lexical reading may give place to nonlexical strategies when special circumstances require it. What these circumstances are appears to depend on the characteristics of the different writing systems, as indicated by Experiment 3. Probably, unlike in ordinary reading, the unusual nonlexical strategy is hard and time consuming. However, educated adults can switch into it, and whether or not to do so is under their strategic control, even if they are unaware of this (Kihlstrom, 1984; Lewicki, 1986).

Similar conclusions have recently been drawn by Baluch and Besner (1991), who investigated word pronunciation in Persian. In the orthographic system of that language, the spelling-sound correspondence is consistent. However, although the vowels are specified in some written words, which are thus phonologically transparent, vowels are not specified in other words, which are therefore phonologically opaque. Baluch and Besner (1991) found that when pseudowords were included in the experimental list, frequency and semantic priming effects occurred for opaque but not for transparent words, which, however, were pronounced faster than transparent nonwords. In contrast, when pseudowords were not included in the experimental list, frequency and semantic priming effects occurred for both opaque and transparent words. Finally, when no opaque words were included in the list, transparent words showed frequency effects only in the absence of nonwords. When these were included, transparent words were pronounced faster than transparent nonwords. Evidently, how transparent words are pronounced in Persian depends on the specific conditions under which reading takes place.

Evidence for strategic effects touches on the last point raised in the introduction-namely, the adequacy of word pronunciation as an experimental task. On the one hand, the present findings suggest that, as long as appropriate lists are created, naming can safely be used with languages similar to Italian as well as with those with a deep orthography. On the other hand, the ever more popular view, that lexical decision is open to postlexical, strategic factors, whereas naming reflects automatic aspects of language comprehension, may be misleading. It is certainly true that lexical decision is a complex task, and strategic effects on it are well documented (Seidenberg, Waters, Sanders, \& Langer, 1984). However, one should ignore neither the existence of data suggesting automaticity in lexical decision (de Groot, 1985; Fischler, 1977; Neely, 1977), nor the existence of data casting doubts on the insensitivity of naming to strategic factors (Balota \& Chumbley, 1985; Keefe \& Neely, 1990; Stanovich \& West, 1983). Thus, although our knowledge of these and other tasks is progressing rather quickly (and the present paper may be a contribution in this direction), it is still wiser to consider "both types of latencies as dependent variables" (Forster, 1981), rather than to simply accept one and discard the other.

\section{REFERENCES}

ANDREws, S. (1982). Phonological recoding: Is the regularity effect consistent? Memory \& Cognition, 10, 565-575.

Balota, A. D. \& Chumbley, J. I. (1985). The locus of word-frequency effects in the pronunciation task: Lexical access and/or production? Journal of Memory \& Language. 24, 89-106.

BALUCH, B., BeSNer, D. (1991). Strategic use of lexical and nonlexical routines in visual word recognition: Evidence from oral reading in Persian. Joumal of Experimental Psychology: Leaming, Memory, \& Cognition, 17, 644-652.

BECKER, C. A. (1979). Semantic context and word frequency effects in visual word recognition. Joumal of Experimental Psychology: Human Perception \& Performance, 5, 252-259.

BECKER, C. A. (1980). Semantic context effects in visual word recognition: An analysis of semantic strategies. Memory \& Cognition, 8 , 493-512.

Bentin, S., BArgai, N., a KATZ, L. (1984). Orthographic and phonemic coding for lexical access: Evidence from Hebrew. Joumal of Experimensal Psychology: Leaming. Memory, \& Cognition, 10. 353-368.

Bentin, S., Frost, R. (1987). Processing lexical ambiguity and visual word recognition in a deep orthography. Memary \& Cognition, 15 . 13-23.

BESNER, D. (1987). On the relationship between orthographies and phonologies in visual word recognition. In D. A. Allport, D. Mackay, W. Prinz, \& E. Scheerer (Eds.), Language perception and production (pp. 211-226). New York: Academic Press.

BESNER, D. , HiLDebrandT, N. (1987). Orthographic and phonological codes in the oral reading of Japanese Kans. Journal of Experimeneal Psychology: Learning, Memory. \& Cognition, 13, 335-343.

Bruning, J. L., \&INTz, B. L. (1977). Computational handbook of statistics. Glenview, IL: Scott, Foresman.

Carello, C., Lukatela, G., Turvey, M. T. (1988). Rapid naming is affected by association but not by symtax. Memory \& Cognition, 16, 187-195.

Chumbley, J. I., Balota, D. A. (1984). A word's meaning affects the decision in lexical decision. Memory \& Cognition, 12, 590-606.

CоLомво, L. (1991). The role of lexical stress in word recognition and pronunciation. Psychological Research, 53, 71-79.

Colthenrt, M. (1978). Lexical access in simple reading tasks. In G. Underwood (Ed.), Strategies of information processing (pp. 151216). London: Academic Press.

Coltheart, M., Besner, D., Jonasson, J. T., \& Davelaar, E. (1979). Phonological recoding in the lexical decision task. Quarterly Journal of Experimental Psychology, 31, 489-507.

Davelaar, E., Coltheart, M., Besner, D., Jonasson, J. T. (1978). Phonological recoding and lexical access. Memory \& Cognition, 6, 391-402.

DE Groot, A. M. B. (1984). Primed lexical decision: Combined effects of the proportion of related prime-target pairs and the stimulusonset asynchrony of prime and target. Quarterly Joumal of Experimental Psychology, 36A, 253-280.

DE GroOt, A. M. B. (1985). Word-context effects in word naming and 
lexical decision. Quarterly Joumal of Experimental Psychology, 37A, 281-297.

Feldman, L. B., TuRvey, M. T. (1983). Word recognition in SerboCroatian is phonologically analytic. Journal of Experimental Psychol ogy: Human Perception \& Performance, 9, 288-298.

FisCHLER, 1. (1977). Semantic facilitation without association in a lexical decision task. Memony \& Cognition, 5, 335-339.

Forster, K. I. (1979). Levels of processing and the structure of the language processor. In W. E. Cooper \& E. C. Walker (Eds.), Sentence processing (pp. 27-85). Hillsdale, NJ: Erlbaum.

Forster, K. I. (1981). Priming and the effects of sentence and lexical contexts on naming time: Evidence for automatic processing. Quarterly Journal of Experimental Psychology, 33A, 465-495.

Forster, K. I., ChAmbers, S. M. (1973). Lexical access and naming time. Joumal of Verbal Learning \& Verbal Behavior, 12, 627-635.

Frederiksen, J. R., KrolL, J. F. (1976). Spelling and sound: Approaches to the internal lexical. Joumal of Experimental Psychology. Human Perception \& Performance, 2, 361-379.

Frost, R., Katz, L., Bentin, S. (1987). Strategies for visual word recognition and orthographical depth: A multilingual comparison. Journal of Experimental Psychology: Human Perception \& Performance, 13, 104-115.

Glanzer, M., Ehrenreich, S. L. (1979). Structure and search in the internal lexicon. Joumal of Verbal Leaming \& Verbal Behavior. 18, 381-398.

HENDERSON, L. (1982). Orthography and visual word recognition in reading. New York: Academic Press.

Hudson, P. T. W., Bergman, M. W. (1985). Lexical knowledge in word recognition: Word length and word frequency in naming and lexical decision tasks. Joumal of Memory \& Language, 24, 46-58.

Istituto di Linguistica Computazionale di Pisa (1989). Corpus di Barcellona. Unpublished manuscript.

KatZ, L., Feldman, L. B. (1983). Relation between pronunciation and recognition of printed words in deep and shallow orthographies. Journal of Experimental Psychology: Learning, Memory, \& Cognition, 9, 157-166.

KeEfE, D. E., Neely, J. H. (1990). Semantic priming in the pronunciation task: The role of prospective prime-generated expectancies. Memory \& Cognition, 18, 289-298.

Kinlstrom, J. (1984). Conscious, subconscious, unconscious: A cognitive perspective. In K. S. Bowers \& D. Meichenbaum (Eds.), The unconscious reconsidered (pp. 149-211). New York: Academic Press.

LEWICK, P. (1986). Processing information about covariations that cannot be articulated. Joumal of Experimental Psychology: Learning. Memory, \& Cognition, 13, 135-146.

lukatela, G., Feldman, L. B., Turvey, M. T., Carello, C., * KATZ, L. (1989). Context effects in bi-alphabetic word perception. Journal of Memory \& Language, 28, 214-236.

LUPKER, S. J. (1984). Semantic priming without association: A second look. Journal of Verbal Leaming \& Verbal Behavior, 23, 709-733.

Meyer, D. M., Schvaneveldt, R. W., \&uddy, M. (1974). Functions of graphemic and phonemic codes in visual word-recognition. Memory \& Cognition, 2, 309-321.

NEELY, J. H. (1977). Semantic priming and retrieval from lexical memory: Roles of inhibitionless spreading activation and limited-capacity attention. Joumal of Experimental Psychology: General, 106, 226-254.

PAlermo, D. S., \& Jenkins, J. J. (1964). Word association norms: Gradeschool through college. Minneapolis: University of Minnesota Press.

Parisi, D., Pizzamigloo, G. (1967). Dati quantitativi sulle associazioni verbali di studenti italiani. Rome: Bulzoni.

Patterson, K. E. (1982). The relationship between reading and phonological coding: Further neuropsychological observations. In A. W. Ellis (Ed.), Normality and pathology in cognitive functions (pp. 77112). London: Academic Press.

Postman, L., \& KePPel, G. (EDs.) (1970). Norms of word association. New York: Academic Press.

Rosson, M. B. (1985). The interaction of pronunciation rules and lexical representations in reading aloud. Memory \& Cognition, 13, 90-99.

Rozin, P., Gleitman, L. R. (1977). The structure and acquisition of reading. In A. S. Reber \& D. L. Scarborough (Eds.), Toward a psychology of reading (pp. 55-141). Hillsdale, NJ: Erlbaum.

Rubenstein, H., Lewis, S. S., \& Rubenstein, M. A. (1971). Homographic entries in the internal lexicon: Effects of systematicity and relative frequency of meaning. Journal of Verbal Learning \& Verbal Behavior, 10, 57-62.

Schreuder, R., Flores d'Arcais, G. B., Glazenborg, G. (1984). Effects of perceptual and conceptual similarity in semantic priming. Psychological Research, 45, 339-354.

SeIDENBERG, M. S. (1985a). The time course of information activation and utilization in visual word recognition. In D. Besner, T. G. Walker, \& G. E. Mackinnan (Eds.), Reading research: Advances in theory and practice (Vol. 5, pp. 199-252). New York: Academic Press.

SEIDENBERG, M. S. (1985b). The time course of phonological code activation in two writing systems. Cognition, 19, 1-30.

Seidengerg, M. S., MCClelland, J. L. (1989). A distributed, developmental model of word recognition and naming. Psychological Review, 96, 523-568.

Seidenberg, M. S., Vidanovic, S. (1985, November). Word recognition in Serbo-Croatian and English: Do they differ? Paper presented at the meeting of the Psychonomic Society, Boston.

Seidenberg, M. S., Waters, G. S., Barnes, M. A. . Tanenhaus, M. K. (1984). When does irregular spelling or pronunciation influence word recognition? Joumal of Verbal Leaming \& Verbal Behavior. 23, 383-404.

Seidenberg, M. S., Waters, G. S., Sanders, M., Langer. P. (1984). Pre- and postlexical loci of contextual effects on word recognition. Memory \& Cognition, 12, 315-328.

Stanovich, K. E. \& WEST, R. F. (1983). On priming by sentence context. Joumal of Experimental Psychology: General, 112. 1-36.

SWINNEY, D. A. (1979). Lexical access during sentence comprehension: (Re)consideration of context effects. Journal of Verbal Leaming \& Verbal Behavior, 6, 645-659.

TABOssI, P. (1988). Accessing lexical ambiguity in different types of sentential contexts. Joumal of Memory \& Language, 27, 324-340,

Tanenhaus, M. K., Leiman, J. M., Seidenberg, M. S. (1979). Evidence for multiple stages in the processing of ambiguous words in syntactic contexts. Jourmal of Verbal Leaming \& Verbal Behavior. 18, $427-440$.

Theios, J., MuISE, J. G. (1977). The word identification process in reading. In N. J. Castellan, Jr., D. B. Pisoni, \& G. R. Potts (Eds.), Cognitive theory (Vol. 2. pp. 289-321). Hillsdale, NJ: Erlbaum.

Turvey, M. T., Feldman, L. B., Lukatela, G. (1984). The SerboCroatian orthography constrains the reader to a phonologically analytic strategy. In L. Henderson (Ed.), Orthographies and reading: Perspectives from cognitive psychology, neuropsychology, and linguistics (pp. 81-89). London: Erlbaum.

Tweedy, J. R., Lapinski, R. H., \& SchVaneveldt, R. W. (1977) Semantic-context effects on word recognition: Influence of varying the proportion of items presented in an appropriate context. Memory \& Cognition, 5, 8489.

WATER, G. S., \& SeIDENBERG, M. S. (1985). Spelling-sound effects in reading: Time-course and decision criteria. Memory \& Cognition, 13, 557-572.

West, R. F., Stanovich, K. E. (1982). Source of inhibition in experiments on the effect of sentence context on word recognition. Journal of Experimental Psychology: Learning, Memory, \& Cognition. 8, 385-399.

\section{APPENDIX A}

Associated and Unrelated Word Pairs Used in Experiments 1 and 2 in Italian and in Their Translation Into English Italian English

Associated

ARGENTO-ORO

COLLINA-MONTE

CANE-GATTO

CARNE-PESCE

FORCHETTA-COLTELLO

GUARDIA-LADRO
SILVER-GOLD HILL-MOUNTAIN DOG-CAT MEAT-FISH KNIFE -FORK GUARD-THIEF 
APPENDIX A (Continued)

INCHIOSTRO-NERO

LANA-SETA

LEONE-FEROCE

LIMONE-ARANCIA

LUNA-PIENA

MACCHINA-VELOCE

MANO-PIEDE

PANE-VINO

PERA-MELA

PIOMBO-PESANTE

PIUMA-LEGGERA

PRATO-VERDE

SANGUE-ROSSO

ZUCCHERO-DOLCE

Unrelated

ALBERO-BAMBINO
AZZURRO-BARBA
CIELO-LIQUORE
FINESTRA-ONDA
GINOCCHIO-FAMOSO
GOLA-ALLEGRA
LATTE-GAMBA
LIBRO-VELENO
LUPO-ORTO
MARITO-PONTE
NASO-MATTINA
ORECCHIO-LAGO
PALLA-SECCA
PEPE-CIECO
PRUGNA-GIALLO
RAGNO-BOMBA
REGINA-BUE
STELLA-APE
VETRO-PAPA
VOLPE-ACQUA

TREE-CHILD
BLUE-BEARD
SKY-LIQUEUR
WINDOW-WAVE
KNEE-FAMOUS
THROAT-CHEERFUL
MILK-LEG
BOOK-POISON
WOLF-ORCHARD
HUSBAND-BRIDGE
NOSE-MORNING
EAR-LAKE
BALL-DRY
PEPPER-BLIND
PLUM-YELLOW
SPIDER-BOMB
QUEEN-OX
STAR-BEE
GLASS-FATHER
FOX-WATER

INK-BLACK

WOOL-SILK

LION-WILD

LEMON-ORANGE

MOON-FULL

CAR-FAST

HAND-FOOT

BREAD-WINE

PEAR-APPLE

LEAD-HEAVY

FEATHER-LIGHT

MEADOW-GREEN

BLOOD-RED

SUGAR-SWEET

APPENDIX B (Continued)

\section{APPENDIX C}

SEA-WATER

BREAD-WINE

PEAR-APPLE

MEADOW-GREEN

SALT-PEPPER

BLOOD-RED

SUGAR-SWEET

List of the 40 Pairs of Italian Words Used in Experiment 4 in Their Original Form and in the English Translation

\begin{tabular}{|c|c|}
\hline Italian & English \\
\hline AGO-FILO & NEEDLE-THREAD \\
\hline ALTO-BASSO & HIGH-LOW \\
\hline ARGENTO-ORO & SILVER-GOLD \\
\hline BELLO-BRUTTO & BEAUTIFUL-UGLY \\
\hline CALDO-FREDDO & HOT-COLD \\
\hline CANE-GATTO & DOG-CAT \\
\hline CAPRA-PECORA & GOAT-SHIP \\
\hline CARNE-PESCE & MEAT-FISH \\
\hline CIELO-AZZURRO & SKY-BLUE \\
\hline COGNOME-NOME & SURNAME-NAME \\
\hline CORTO-LUNGO & SHORT-LONG \\
\hline DIAVOLO-ANGELO & DEVIL-ANGEL \\
\hline FORCHETTA-COLTELLO & FORK-KNIFE \\
\hline FORMAGGIO-TOPO & CHEESE-MOUSE \\
\hline FORTE-DEBOLE & STRONG-WEAK \\
\hline FRATELLO-SORELLA & BROTHER-SISTER \\
\hline GIOVANE-VECCHIO & YOUNG-OLD \\
\hline INCHIOSTRO-NERO & INK-BLACK \\
\hline LAMPADA-LUCE & LAMP-LIGHT \\
\hline LAMPONI-FRAGOLE & RASPBERRIES-STRAWBERRIES \\
\hline LENTO-VELOCE & SLOW-FAST \\
\hline LEONE-FEROCE & LION-FIERCE \\
\hline LIMONE-ARANCIA & LEMON-ORANGE \\
\hline LIQUIDO-SOLIDO & LIQUID-SOLID \\
\hline LUNA-PIENA & MOON-FULL \\
\hline MADRE-BAMBINO & MOTHER-CHILD \\
\hline MANO-PIEDE & HAND-FOOT \\
\hline MASCHIO-FEMMINA & MALE-FEMALE \\
\hline MINIMO-MASSIMO & MINIMUM-MAXIMUM \\
\hline MOGLIE-MARITO & WIFE-HUSBAND \\
\hline NOTE-MUSICA & NOTES-MUSIC \\
\hline PANE-VINO & BREAD-WINE \\
\hline PIOMBO-PESANTE & LEAD-HEAVY \\
\hline PIUMA-LEGGERA & FEATHER-LIGHT \\
\hline PORTA-FINESTRA & DOOR-WINDOW \\
\hline PRATO-VERDE & MEADOW-GREEN \\
\hline PUBBLICO-PRIVATO & PUBLIC-PRIVATE \\
\hline SCURO-CHIARO & DARK-LIGHT \\
\hline TAVOLO-SEDIA & TABLE-CHAIR \\
\hline ZUCCHERO-DOLCE & SUGAR-SWEET \\
\hline
\end{tabular}

List of the 18 Pairs of Italian Words Used in Experiment 3 in Their Original Form and in the English Translation

\begin{tabular}{ll}
\hline \multicolumn{1}{c}{ Italian } & \multicolumn{1}{c}{ English } \\
\hline ARGENTO-ORO & SILVER-GOLD \\
CANE-GATTO & DOG-CAT \\
CARNE-PESCE & MEAT-FISH \\
COLLINA-MONTE & HILL-MOUNTAIN \\
FIUME-LAGO & RIVER-LAKE \\
GUARDIA-LADRO & GUARD-THIEF \\
INCHIOSTRO-NERO & INK-BLACK \\
LAMPADA-LUCE & LAMP-LIGHT \\
LANA-SETA & WOOL-SILK \\
LATTE-BIANCO & MILK-WHITE \\
LUNA-PIENA & MOON-FULL
\end{tabular}

(Manuscript received February 17, 1989;

revision accepted for publication October 4,1991 .) 